\title{
ATIVIDADE ANTIMICROBIANA DO ÓLEO ESSENCIAL DO CAPIM LIMÃO (Cymbopogon citratus) E SUA INTERAÇÃO COM OS COMPONENTES DOS ALIMENTOS
}

\author{
TEREZINHA FEITOSA MACHADO* \\ RITA DE CÁSSIA ALVES PEREIRA** \\ CIVITA TEIXEIRA DE SOUSA *** \\ VALÉRIA CHAVES VASCONCELOS BATISTA ${ }^{* * * * *}$
}

\begin{abstract}
Determinou-se o potencial antimicrobiano do óleo essencial (OE) de Cymbopogon citratus (DC) Stapf e o efeito dos componentes dos alimentos sobre sua eficácia. O potencial antimicrobiano do óleo foi determinado pela presença de zona de inibição de crescimento e concentração inibitória mínima contra Listeria monocytogenes, $L$. innocua, Staphylococcus aureus, Escherichia coli, Pseudomonas aeruginosa e Salmonella choleraesuis. O efeito dos componentes dos alimentos e do $\mathrm{pH}$ sobre a eficácia antimicrobiana do óleo foi monitorado pelo crescimento de $L$. monocytogenes em meios de cultura modelos, constituídos de amido de batata $(0,1,5$ e 10 $\%)$, extrato de carne $(1,5,3,6$ e $12 \%)$, óleo de girassol $(0,5$ e $10 \%$ ) e caldo tripticase de soja (TSB) em pH 4, 5, 6 e 7 . O OE mostrou eficácia contra todas as espécies bacterianas testadas. $\mathrm{O}$ efeito antimicrobiano do óleo variou em função da concentração do componente manipulado. Proteínas e lipídios apresentaram impacto negativo na eficácia do OE; quanto maior a concentração destes componentes nos meios maiores foram as médias do crescimento bacteriano. $O$ amido apresentou impacto negativo na eficácia do óleo nas concentrações de $1 \%$ e $5 \%$. Contudo, na mais alta concentração avaliada (10 \%) observou-se um declínio no crescimento bacteriano. A atividade antimicrobiana do OE aumentou com a diminuição do $\mathrm{pH}$. Os resultados deste estudo comprovaram a eficácia antimicrobiana do OE do C. citratus para agentes patogênicos e bactérias deterioradoras de alimentos, verificando-se maior eficiência em alimentos proteicos e amiláceos em pH ácido.
\end{abstract}

PALAVRAS-CHAVE: CYMBOPOGON CITRATUS; ÓLEOS ESSENCIAIS; AÇÃO ANTIBACTERIANA.

\footnotetext{
*Doutora em Bioquímica, pesquisadora, CNPAT (Centro Nacional de Pesquisa Agroindústria Tropical), Fortaleza, CE (e-mail: terezinha.feitosa@embrapa.br).

**Doutora em Fitotecnia, pesquisadora, CNPAT, Fortaleza, CE, (e-mail: rita.pereira@embrapa.br)

"**Mestre em Engenharia química, UFC, Fortaleza, CE, (E-mail: civitatsou@ig.com.br).

${ }^{* * * *}$ Graduanda em Engenheira de alimentos, UFC, Fortaleza, CE, (E-mail: valeriacvb@ig.com.br).
} 


\section{INTRODUÇÃO}

As doenças alimentares de origem microbiológica constituem problema crescente em saúde pública e causa importante na redução da produtividade econômica, tanto em países desenvolvidos como em vias de desenvolvimento (WHO, 2002). Os inúmeros fatores que, interrelacionados, contribuem para agravar o risco de ocorrência dessas doenças incluem as inovações na agropecuária, mudanças nos hábitos alimentares, evolução tecnológica e demais alterações a nível ambiental, econômico e social (GANDHI e CHIKINDAS, 2007).

Os microorganismos apresentam enorme facilidade de evoluir por mutação e recombinação genética, conduzindo ao aparecimento de espécies ou linhagens com maior virulência e com grande capacidade de sobrevivência perante antimicrobianos e fatores ambientais adversos (BRANDL, 2006; O'BRIEN, 2002). O aumento da resistência bacteriana aos antibióticos induz ao aparecimento de estirpes mais virulentas, com capacidade de atravessar barreiras naturais de defesa do organismo e de se tornarem patogênicos, mesmo quando presentes em baixo número (SANTOS e CUNHA, 2007). Por isso, há um interesse considerável na identificação de novas classes de antimicrobianos, que possam ser úteis para a conservação de alimentos.

Os óleos essenciais (CE) de plantas têm sido muito utilizados como agentes flavorizantes em alimentos, bebidas, produtos de confeitaria entre outros. Sua versátil composição e o grande espectro antimicrobiano, associados à sua baixa toxicidade, os tornam possíveis agentes naturais para a conservação de alimentos (OUSSALAH, CAILLET e LAROIX, 2006). Diversas referências sobre a atividade antimicrobiana de OE estão disponíveis na literatura (BAKKALI et al., 2008; BURT, 2007; SCHELZ, MOLNAR HOHMANN, 2006). Essa atividade é atribuída à presença de compostos fenólicos e terpenos, que na sua forma pura têm mostrado atividade antibacteriana e antifúngica (BOZIN et al, 2006). Análises químicas desses óleos têm mostrado que os principais compostos ativos são carvacrol, timol, citral, eugenol, limoneno, pineno, linalol e seus precursores (DEMETZOS e PERDETZOGLOU, 2001). No entanto, muitas vezes há grandes diferenças na atividade antibacteriana relatada do óleo da mesma planta. As razões para esta variabilidade podem ser devidas às fontes geográficas, épocas de colheita, genótipo, clima e método de extração, que influenciam a composição química e as proporções relativas de cada constituinte no óleo essencial da planta (BURT, 2004; HOLLEY e PATEL, 2005).

A espécie Cymbopogon citratus, pertencente à família Poaceae, é originária da Índia e largamente distribuída por vários países tropicais. No Brasil assume diferentes sinonímias como capim-limão, capim-santo, erva-cidreira entre outras. A medicina popular utiliza o chá ou abafado, preparado a partir de suas folhas, como calmante, analgésico, antipirético, antirreumático, diurético, e em distúrbios digestivos (FERREIRA e FONTELES, 1989). Estudos sugerem que a atividade antibacteriana de $C$. citratus reside principalmente nos componentes $\alpha$-e $\beta$-citral presentes no óleo (ONAWUNMI, YISAK e OGUNLANA, 1984).

Considerando o uso popular, o objetivo do presente estudo foi avaliar a eficácia do OE de C. citratus contra micro-organismos patogênicos e deterioradores de alimentos e avaliar o efeito dos componentes majoritários dos alimentos sobre sua eficácia.

\section{MATERIAL E MÉTODOS}

\subsection{MATERIAL VEGETAL}

Amostras de folhas de C. citratus foram obtidas de plantas proveniente do Campo Experimental da Embrapa Agroindústria Tropical, localizado no município de Paraipaba, Ceará. Uma sub-amostra da espécie foi depositada no Herbário da Embrapa Recursos Genéticos e Biotecnologia sob o número de Tombo 73.792. 


\subsection{EXTRAÇÃO DO ÓLEO ESSENCIAL}

O material vegetal foi submetido à hidrodestilação por $4 \mathrm{~h}$, utilizando-se aparelho do tipo Clevenger. $\mathrm{O} O E$ separado por centrifugação foi submetido à secagem com $\mathrm{Na}_{2} \mathrm{SO}_{4}$, transferido para frascos de vidro âmbar com tampa rosqueada e armazenado sob refrigeração até o momento das análises (CRAVEIRO, MATOS e ALENCAR, 1976).

\subsection{MICROORGANISMOS}

As espécies bacterianas usadas neste estudo foram Escherichia coli ATCC 10536, Listeria innocua ATCC 19115, Listeria monocytogenes ATCC 33090, Pseudomonas aeruginosa ATCC 9027, Salmonella choleraesuis ATCC 10708 e Staphylococcus aureus ATCC 6538P. Todas as espécies foram mantidas a - $80{ }^{\circ} \mathrm{C}$ em caldo Infusão de cérebro e coração (caldo BHI, Merck) contendo 20 $\%$ de glicerol. As culturas de trabalho foram preparadas pelo subcultivo de $100 \mu \mathrm{L}$ de cada cultura estoque em $9 \mathrm{~mL}$ de caldo $\mathrm{BHI}$ e incubadas a $35^{\circ} \mathrm{C}$ por $12 \mathrm{~h}$. Após esse período, as culturas tiveram sua densidade celular ajustada em solução salina $0,85 \%$ estéril, de modo a se obter turbidez comparável à do tubo 0,5 da escala de McFarland (Biomerieux Inc.), o que resulta em suspensão microbiana contendo aproximadamente $10^{8} \mathrm{UFC} / \mathrm{mL}$.

\subsection{ENSAIO DA ATIVIDADE ANTIMICROBIANA}

Para a avaliação da atividade antimicrobiana utilizou-se o método de difusão em ágar conforme norma M2-A8 do Clinical and Laboratory Standards Instituite- CLSI/NCCLS (ANVISA, 2003a). Suspensões microbianas foram semeadas na superfície de ágar Mueller-Hinton (Difco). Com perfurador estéril foram feitos poços de $5 \mathrm{~mm}$ de diâmetro interno, aos quais foram adicionados $25 \mu$ do OE de $C$. citratus em concentrações binárias, preparadas em Tween $801 \%$. As placas inoculadas foram mantidas em temperatura ambiente durante 30 minutos para permitir a difusão do óleo e, posteriormente, incubadas em $35{ }^{\circ} \mathrm{C} / 24 \mathrm{~h}$. A atividade antimicrobiana foi avaliada pela medida do diâmetro dos halos de inibição do crescimento microbiano em torno dos poços. Excluindo-se $5 \mathrm{~mm}$ referentes ao diâmetro dos poços, os halos com diâmetros iguais ou superiores a $7 \mathrm{~mm}$ foram considerados indicativos de sensibilidade bacteriana ao óleo. Soluções estéreis de Tween 80 (VETEC) $1 \%$ e de amicacina (Sigma-Aldrich) 1,2mg/mL, foram usadas como controles negativo e positivo do experimento, respectivamente. Todos os ensaios foram realizados em duplicata.

\subsection{DETERMINAÇÃO DA CONCENTRAÇÃO INIBITÓRIA MÍNIMA (CIM) E DA CONCENTRAÇÃO BACTERICIDA MÍNIMA (CBM)}

A CIM do OE para as cepas bacterianas foi determinada pelo método da microdiluição em caldo de cultura (ANVISA, 2003b). Suspensões bacterianas com densidade celular ajustada para $10^{8}$ $\mathrm{UFC} / \mathrm{mL}$, como descrito anteriormente, foram diluídas em caldo BHI estéril para, aproximadamente, $10^{6} \mathrm{UFC} / \mathrm{mL}$. Aos poços-teste, de placas de microdiluição com 96 poços, foram adicionados $80 \mu \mathrm{L}$ das suspensões microbianas, $100 \mu \mathrm{L}$ de caldo $\mathrm{BHI}$ (Merck) e $20 \mu \mathrm{L}$ de diluições binárias do OE de C. citratus. Nos poços-controle foram adicionados $80 \mu \mathrm{L}$ das suspensões microbianas, $100 \mu \mathrm{L}$ de caldo BHI e $20 \mu \mathrm{L}$ de solução estéril de amicacina $1,2 \mathrm{mg} / \mathrm{mL}$ ou de Tween $801 \%$. Após incubação a $35{ }^{\circ} \mathrm{C}$ por 24 horas, a menor concentração dos óleos na qual não foi evidenciado crescimento microbiano foi determinada como CIM.

A CBM foi determinada de acordo com a metodologia descrita por Baron et al. (1994). Alíquotas de $50 \mu \mathrm{L}$ foram removidas dos poços que não apresentaram turvação visível nas microplacas usadas na determinação da CIM e semeadas na superfície de Ágar Plate Count 
(Merck). Após incubação durante 24 horas a $35^{\circ} \mathrm{C}$ foi realizada a contagem das colônias crescidas sobre a superfície do meio sólido. A concentração do OE capaz de inibir o crescimento microbiano a menos de $0,1 \%$ do inóculo inicial foi considerada como a CBM. Todos os ensaios foram realizados em duplicata.

\subsection{EFEITO INTERATIVO DO ÓLEO ESSENCIAL COM OS COMPONENTES DOS ALIMENTOS E PH}

O efeito dos constituintes de alimentos e do pH sobre a eficácia antimicrobiana do OE do C. citratus foi avaliado utilizando-se vários meios de cultura modelos e $L$. monocytogenes ATCC 33090 como linhagem indicadora (Gutierrez et al., 2008). Utilizou-se a CIM do óleo $(0,68 \mathrm{mg} / \mathrm{mL}$ ), previamente estabelecida para a espécie microbiana. Os meios de cultura modelos utilizados foram os seguintes: (1) amido de batata solúvel em água ( $0 ; 1 ; 5 ; 10 \%$, Difco) em caldo tripticase de soja (TSB); (2) extrato de carne $(1,5 ; 3 ; 6 ; 12 \%$, Difco) em água destilada e, (3) óleo de girassol (0; 5 ; $10 \%$ ) em TSB. Os meios de cultura modelos contendo amido e extrato de carne foram autoclavados antes do uso. Para o meio de cultura modelo contendo óleo, o óleo de girassol foi autoclavado separadamente e depois adicionado ao TSB estéril. Tween 80 (Merck) $1 \%$ foi esterilizado por filtração e adicionado ao meio para facilitar a mistura e estabilizar a emulsão. $\mathrm{O}$ pH dos meios de cultura modelos foi ajustado a 7,2. Para determinar o efeito do $\mathrm{pH}$ sobre a eficácia do óleo, TSB foi ajustado para $\mathrm{pH}$ 4, 5, 6 e 7 com solução de $\mathrm{HCl} 1 \mathrm{~N}$.

$\mathrm{O}$ crescimento de $L$. monocytogenes em cada meio de cultura modelo adicionado do OE de C. citratus foi monitorado em placas de microdiluição com 96 poços. Para cada poço da microplaca foram adicionados $80 \mu \mathrm{L}$ do meio, $20 \mu \mathrm{L}$ do OE e $100 \mu \mathrm{L}$ de da suspensão microbiana a $10^{6} \mathrm{UFC} / \mathrm{mL}$. Os controles positivos continham o meio de cultura modelo inoculado com o microorganismo sob investigação e os controles negativos continham o meio de cultura modelo com o óleo essencial sem o microorganismo. O crescimento microbiano foi avaliado a $490 \mathrm{~nm}$ em espectrofotômetro (Varian cary), após 24 horas. Todos os testes foram realizados em duplicado e, em seguida, replicados.

\subsection{ANÁLISE ESTATÍSTICA}

Métodos estatísticos convencionais foram utilizados para calcular médias e desvios-padrão de dois ensaios simultâneos. Para a comparação das médias foi utilizado o teste de Tukey ao nível de $5 \%$ de significância.

\section{RESULTADOS E DISCUSSÃO}

\subsection{ENSAIO DA ATIVIDADE ANTIMICROBIANA}

Os resultados da atividade antibacteriana do OE de C. citratus estão apresentados na Tabela 1. O OE mostrou-se eficaz, principalmente, contra as bactérias Gram positivas. Esses resultados corroboram relatos anteriores que justificam maior susceptibilidade dessas bactérias devido à presença da membrana externa em suas células, que proporciona forte barreira aos óleos (BURT, 2004; CALSAMIGLIA et al., 2007; AL-REZA et al., 2010). Contudo, o efeito antibacteriano dos OE não é uniforme entre as espécies bacterianas e pode variar em função de sua composição e espécie estudada (FISHER e PHILLIPS, 2008) As linhagens testadas neste estudo apresentaram níveis de sensibilidades diferentes quanto à procedência do $\mathrm{OE}$, mostrando maior susceptibilidade ao óleo proveniente das folhas frescas, nas quais foram observadas zonas de inibição do crescimento nas menores concentrações testadas. A maior eficácia do OE ocorreu contra S. aureus, apresentando resultados semelhantes para os óleos de ambos os tipos de folhas, frescas e secas. 


\section{TABELA 1 - ZONA DE INIBIÇÃO DO ÓLEO ESSENCIAL DE FOLHAS FRESCAS E SECAS DE C. CITRATUS}

\begin{tabular}{l|c|c|c|c|c|c}
\hline \multirow{2}{*}{ Microorganismos } & \multicolumn{2}{c}{ Folhas frescas } & \multicolumn{2}{c}{ Folhas secas } & \multicolumn{2}{c}{ Controle* } \\
& $\begin{array}{c}\text { ZI ** } \\
(\mathrm{mm})\end{array}$ & $\begin{array}{c}\text { Conc } \\
\%\end{array}$ & $\begin{array}{c}\text { ZI } \\
(\mathrm{mm})\end{array}$ & $\begin{array}{c}\text { Conc } \\
\%\end{array}$ & $\begin{array}{c}\text { ZI } \\
(\mathrm{mm})\end{array}$ & $\begin{array}{c}\text { Conc } \\
\mathrm{mg} / \mathrm{mL}\end{array}$ \\
\hline S. aureus & $10 \pm 2,0$ & 1.5 & $9,5 \pm 1,0$ & 1.5 & $35.0 \pm 0,0$ & 1.2 \\
L.monocytogenes & $9 \pm 0,9$ & 1,5 & $12,5 \pm 4,0$ & 6,3 & $44,1 \pm 7,5$ & 1.2 \\
L. innocua & $9 \pm 0.9$ & 1,5 & $12,1 \pm 2,2$ & 3 & $42,9 \pm 7,8$ & 1.2 \\
E. coli & $9,3 \pm 3,3$ & 6,3 & $9,8 \pm 3.4$ & 50 & $30.8 \pm 0,9$ & 1.2 \\
P. aeruginosa & $9,9 \pm 1,0$ & 25 & $10,3 \pm 0.9$ & 50 & $34,5 \pm 4,5$ & 1.2 \\
S. choleraesuis & $9.1 \pm 0.3$ & 25 & $10,3 \pm 2,1$ & 50 & $34,9 \pm 5,1$ & 1.2 \\
\hline
\end{tabular}

*Controle: amicacina. ${ }^{*}$ ZI: zona de inibição.

\subsection{CONCENTRAÇÃO INIBITÓRIA MÍNIMA (CIM) E CONCENTRAÇÃO BACTERICIDA MÍNI- MA (CBM)}

Os valores obtidos para CIM e CBM do OE de folhas frescas e secas de C. citratus estão apresentados na Tabela 2. Obsevou-se que para $S$. aureus a CIM é igual à CBM $(0,34 \mathrm{mg} / \mathrm{mL})$, indicando que nessa concentração, para esta espécie bacteriana, o efeito do OE é bactericida. Para L. monocytogenes, a CIM $(0,60 \mathrm{mg} / \mathrm{mL})$ e CBM $(0,85 \mathrm{mg} / \mathrm{mL})$ são diferentes, sugerindo que esse óleo na concentração de $0,60 \mathrm{mg} / \mathrm{mL}$ exerce efeito bacteriostático nesse micro-organismo. Nessa linha de interpretação é possível observar que o OE pode apresentar atividade bacteriostática ou bactericida para dada espécie microbiana. Os valores das CIM dos OE determinadas neste estudo são considerados baixos. Segundo Nazer et al (2005), um dos aspectos a ser considerado na aplicação de OE em alimentos é o seu impacto sobre as propriedades organolépticas do produto final, considerando que os principais constituintes do OE são responsáveis por sua fragrância e podem alterar ou exceder os limites aceitáveis no sabor dos alimentos. Além disso, uma vez que a actividade antibacteriana é avaliada in vitro, problema importante para a eficácia in situ de dado OE deriva da sua interacão com os componentes do alimento (SETTANNI et al., 2012). Por essa razão, Burt (2004) sugere que maior concentração de EO pode ser necessária para alcançar o mesmo efeito em alimentos. Assim, a atividade antimicrobiana do OE em baixas concentrações determina quantidade menor do OE para ser adicionado nas matrizes alimentares, diminuindo as variações sensoriais indesejadas.

\section{TABELA 2 - CONCENTRAÇÃO INIBITÓRIA MÍNIMA (CIM) E CONCENTRAÇÃO BACTERICIDA MÍNIMA (CBM) DO ÓLEO ESSENCIAL DE C. CITRATUS.}

\begin{tabular}{lcccc}
\hline \multirow{2}{*}{ Microorganismos } & \multicolumn{2}{c}{ Folhas frescas } & \multicolumn{2}{c}{ Folhas secas } \\
& CIM $(\mathrm{mg} / \mathrm{mL})$ & $\mathrm{CB} \mathrm{M}(\mathrm{mg} / \mathrm{mL})$ & $\begin{array}{c}\text { CIM }(\mathrm{mg} / \mathrm{mL}) \\
\mathrm{mL})\end{array}$ & CBM $(\mathrm{mg} /$ \\
\hline S. aureus & 0,56 & 0,97 & 0,34 & 0,34 \\
L. monocytogenes & 0,94 & 0,94 & 0,60 & 0,85 \\
L. innocua & 0,62 & 1,25 & 0,68 & 0,85 \\
E. coli & 1,88 & 1,88 & 5,5 & 5,5 \\
S. choleraesuis & 2,51 & 2,51 & 2,29 & 2,29 \\
P. aeruginosa & 2,51 & 2,51 & 2,06 & 2,06 \\
\hline
\end{tabular}




\subsection{EFEITOS INTERATIVOS DOS CONSTITUINTES DOS ALIMENTOS E PH}

As médias do crescimento máximo de L. monocytogenes, determinado por leituras de absorbância a $490 \mathrm{~nm}$ nos meios de cultura modelos, estão indicadas na Tabela 3. O crescimento de L. monocytogenes no meio de extrato de carne contendo o $\mathrm{OE}$ de $C$. citratus foi menor que no meio controle. Contudo, a atividade antimicrobiana do OE diminui significativamente $(p<0,05)$ com o aumento da concentração de proteína no meio. Em ambos os meios de cultura, controle e modelo, observou-se que a maior taxa de crescimento de $L$. monocytogenes ocorreu na maior concentração de proteína testada. Na avaliação do efeito do amido sobre a ação do OE, quatro concentrações de amido foram avaliadas ( $0 \%, 1 \%, 5 \%$ e $10 \%)$. Na ausência de amido $0,68 \mathrm{mg} / \mathrm{mL}$ do OE de C. citratus foi suficiente para causar diminuição significativa do crescimento de L. monocytogenes. Na presença de $1 \%$ e $5 \%$ de amido observou-se um incremento no crescimento microbiano. Todavia, na mais alta concentração desse constituinte (10\%) ocorreu declínio na taxa de crescimento. Esse mesmo comportamento foi observado no meio de cultura controle. A adição de óleo de girassol aos meios de cultura modelos favoreceu significativamente $(p<0,05)$ o crescimento microbiano, indicando efeito negativo do lipídio na eficácia do OE. Entretanto, em todas as concentrações dos componentes analisados (proteína, lipídio e amido), as taxas do crescimento microbiano foram menores que nos controles.

$\mathrm{O}$ efeito do $\mathrm{pH}$ sobre a atividade antimicrobiana do óleo essencial de $C$. citratus foi avaliado usando-se TSB em pH 4, 5, 6 e 7 (Tabela 3). L. monocytogenes cresceu em todos os pHs. Todavia, o crescimento bacteriano nos meios de cultura modelos com o OE em diferentes $\mathrm{pH}$ foi significativamente menor $(p<0,05)$ que o crescimento observado nos controles livres do óleo. $\mathrm{O}$ menor crescimento registrado ocorreu em $\mathrm{pH} 4$, em ambos os meios (modelo e controle). Isto pode ser atribuído tanto ao efeito direto do $\mathrm{pH}$ ou a melhor dissolução do $\mathrm{OE}$ na fase lipídica da membrana bacteriana em pH baixo (KOUTSOUMANIS, LAMBROPOULOU e NYCHAS 1999).

\section{TABELA 3 - CRESCIMENTO MÁXIMO (MMÁX) DE L. MONOCYTOGENES NOS MEIOS DE CULTURA MODELOS CONTENDO 0,68 MG/ML DE ÓLEO ESSENCIAL DE CYMBOPONGO CITRATUS}

\begin{tabular}{|c|c|c|}
\hline $\begin{array}{c}\text { Meio de Cultura } \\
\text { Modelo }\end{array}$ & $\begin{array}{l}\text { Cymbopogon citratus } \\
\left.\mu \text { máx/24h ( } \text { Abs }_{490 \mathrm{~nm}}\right)\end{array}$ & $\begin{array}{c}\text { Controle } \\
\mu \text { máx/24h }\left(\mathrm{Abs}_{490 \mathrm{~nm}}\right)\end{array}$ \\
\hline $\begin{array}{c}\text { Extrato de carne (\%) } \\
1,5 \\
3 \\
6 \\
12 \\
\text { Meio de Amido (\%) } \\
0,0 \\
1 \\
5 \\
10 \\
\text { Meio óleo de girassol(\%) } \\
0,0 \\
5 \\
10 \\
\text { pH no meio TSB } \\
4 \\
5 \\
6 \\
7\end{array}$ & $\begin{array}{l}0,104^{\mathrm{a}} \pm 0,003 \\
0,119^{\mathrm{b}} \pm 0,001 \\
0,149^{\mathrm{c}} \pm 0,002 \\
0,204^{\mathrm{d}} \pm 0,003 \\
0,112^{\mathrm{a}} \pm 0,001 \\
0,139^{\mathrm{b}} \pm 0,003 \\
0,167^{\mathrm{c}} \pm 0,012 \\
0,141^{\mathrm{b}} \pm 0,001 \\
0,106^{\mathrm{a}} \pm 0,003 \\
0,517^{\mathrm{b}} \pm 0,011 \\
0,607^{\mathrm{c}} \pm 0,003 \\
0,091^{\mathrm{a}} \pm 0,002 \\
0,094^{\mathrm{ab}} \pm 0,001 \\
0,096^{\mathrm{b}} \pm 0,001 \\
0,096^{\mathrm{b}} \pm 0,001\end{array}$ & $\begin{array}{l}0,453^{\mathrm{a}} \pm 0,015 \\
0,454^{\mathrm{a}} \pm 0,023 \\
0,464^{\mathrm{a}} \pm 0,032 \\
0,525^{\mathrm{b}} \pm 0,006 \\
0,566^{\mathrm{a}} \pm 0,020 \\
0,646^{\mathrm{b}} \pm 0,008 \\
0,617^{\mathrm{c}} \pm 0,013 \\
0,458^{\mathrm{d}} \pm 0,025 \\
0,604^{\mathrm{a}} \pm 0,012 \\
0,725^{\mathrm{b}} \pm 0,012 \\
0,734^{\mathrm{b}} \pm 0,011 \\
\\
0,226^{\mathrm{a}} \pm 0,011 \\
0,459^{\mathrm{b}} \pm 0,005 \\
0,488^{\mathrm{b}} \pm 0,037 \\
0,611^{\mathrm{c}} \pm 0,003\end{array}$ \\
\hline
\end{tabular}


Na maioria das pesquisas para avaliar a atividade antimicrobiana de óleos essenciais de plantas são utilizadas séries de diluição em ágar ou em caldo e em alguns casos, ambos os ensaios para fins de comparação, pois o dempenho antimicrobiano nos dois sistemas pode variar. A hidrofobicidade dos componentes dos OE é conhecida por limitar o valor dos testes de difusão para estimar com precisão a potência antimicrobiana. Por isso, várias substâncias como etanol, metanol, tween 80, hexano entre outras são utilizadas para dissolver ou estabilizar os óleos nos meios de cultura à base de água (HOLLEY E PATEL, 2005). Gutierrez et al. (2009) compararam as CIM de diversos $\mathrm{OE}$, contra diferentes espécies microbianas, obtidas por três métodos de ensaio: diluição em caldo, diluição em ágar e difusão em ágar. Não observaram diferença significativa das CIM dos ensaios por diluição, mas essas foram significativamente mais baixas que as determinadas pelo método de difusão. Neste estudo valores diferentes foram obtidos entre os dois ensaios realizados. Observou-se que a para $S$. aureus, espécie mais sensível à presença do óleo, as CIM variaram em função da origem do óleo (folhas frescas e folhas secas), fato não observado em relação às zonas de inibição do crescimento microbiano. Para L. monocytogenes, que apresentou zona de inibição de $9 \pm 0,9 \mathrm{~mm}$ de diâmetro na menor concentração $(1,5 \%)$ do OE proveniente de folhas frescas, apresentou menor CIM na presença do OE procedente de folhas secas $(0,60 \mathrm{mg} / \mathrm{mL})$. Para as demais espécies microbianas também foram observados resultados diferentes entre os dois métodos de avaliação. Considerando que a composição química do alimento pode impactar sobre a eficácia antimicrobiana dos OE, Devlieghereet VERMEULEN e DEBEVERE (2004) ressaltam a importância de se analisar a influência dos componentes majoritários dos alimentos sobre a atividade antimicrobiana de qualquer composto antimicrobiano. Burt (2004) sugeriu que o baixo teor de lipídio dos vegetais pode contribuir para o êxito dos OE em produtos frescos. Fato é que, se o OE se dissolve na fase lipídica do alimento, ele estará, relativamente, menos disponível para agir contra as bactérias presentes na fase aquosa. De modo geral, supõe-se que altos níveis de proteína e gordura no alimento protegem, de alguma maneira, as bactérias da ação dos OE (TASSOU, DROSINOS e NYCHAS, 1995). Gutierrez et al., (2008) observaram o efeito protetor desses compostos quando avaliaram o efeito do OE de orégano e de tomilho sobre $L$. monocytogenes. Neste estudo, a atividade antimicrobiana do $\mathrm{OE}$ do $C$. citratus foi maior na presença de proteína e amido. A adição de lipídios no meio de cultura impactou de forma negativa a atividade do OE. Esses resultados corroboram os relatos de Gutierrez et al. (2008).

Outro aspecto importante para otimizar a aplicação dos OE em alimentos é a avaliação da interação desses com os constituintes dos alimentos em diferentes pH. Neste estudo, a elevação da atividade antimicrobiana do OE de $C$. citratus aumentou com a diminuição do pH. Hsieh, MAU e HUANG (2001), observaram que o efeito antimicrobiano de extratos de plantas eram mais eficientes em $\mathrm{pH}$ ácido. Considerando que a hidrofobicidade dos $\mathrm{OE}$ aumenta em valores baixos de $\mathrm{pH}, \mathrm{a}$ susceptibilidade das bactérias aos $\mathrm{OE}$ aumenta em $\mathrm{pH}$ acídico, tornando, consequentemente, mais fácil a dissolução da camada lipídica da membrana celular da bactéria alvo (JUVEN et al., 1994). A maior eficiência do $\mathrm{OE}$ de $C$. citratus em $\mathrm{pH}$ ácido foi confirmada pelo menor crescimento bacteriano entre $\mathrm{pH} 4$ e $\mathrm{pH} 5$

\section{CONCLUSÃO}

O OE de C. Citratus mostrou atividade antimicrobiana para bactérias Gram positivas e Gram negativas, sendo mais eficiente contra as primeiras.

O OE proveniente de folhas frescas apresentou atividade antimicrobiana maior que o de folhas secas.

A atividade antimicrobiana do $\mathrm{OE}$ de $C$. Citratus mostrou-se uma função do constituinte manipulado, apresentando maior eficiência na presença de proteína, amido e pH ácido.

A concentração de $5 \%$ de lipídios reduziu significativamente a atividade antimicrobiana do OE, impactando de forma negativa na eficiência do óleo. 


\section{ABSTRACT \\ THE ANTIMICROBIAL EFFICACY OF LEMON GRASS ESSENTIAL OIL AND ITS INTERACTION WITH FOOD INGREDIENTS}

In the present study was determined the antimicrobial activity of the essential oil (EO) of Cymbopogon citratus - (DC) Stapf and the effect of food components on its effectiveness. The antimicrobial activity of the oil was determined by the presence of the growth inhibition zone and minimum inhibitory concentration against Listeria monocytogenes, L. innocua, Staphylococcus aureus, Escherichia coli, Pseudomonas aeruginosa and Salmonella choleraesuis. The effect of food components and $\mathrm{pH}$ on the antimicrobial efficacy of oil was monitored by the growth of $\mathrm{L}$. monocytogenes in model medias, constituted of potato starch $(0,1,5$ and $10 \%)$, meat extract $(1.5,3$, 6 and $12 \%)$, sunflower oil (0,5 and 10\%) and tripticase soy broth (TSB) at pH 4, 5, 6 and 7 . The EO was effective against all bacterial species tested. The antimicrobial effect of the oil vary depending on the concentration of the component manipulated. Proteins and lipids showed negative impact on the effectiveness of the EO, the higher the concentration of these components in the media were major bacterial growth medium. The starch had a negative impact on the effectiveness of the oil in concentrations of $1 \%$ and $5 \%$. However, the highest concentration evaluated $(10 \%)$ showed a decline in bacterial growth. The antimicrobial activity of EO increased with decreasing $\mathrm{pH}$. The results of this study demonstrate the efficacy of antimicrobial OE C. citratus against pathogens and spoilage bacteria and that has a higher efficiency in protein and starchy foods at acidic $\mathrm{pH}$.

KEY-WORDS: CYMBOPOGON CITRATUS; ESSENTIAL OIL; ANTIBACTERIAL ACTION.

\section{REFERÊNCIAS}

1 AL-REZA, S. M., RAHMAN, A., LEE, J., KANG, S. C. Potential roles of essential oil and organic extracts of Zizyphus jujuba in inhibiting food-borne pathogens. Food Chemistry, v.119, p.981-986, 2010.

2 ANVISA. Metodologia dos testes de sensibilidade a agentes antimicrobianos por diluição para bactéria de crescimento aeróbico:

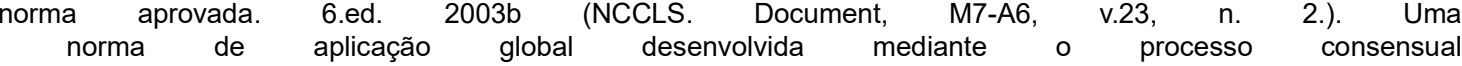
do NCCLS. Disponível em: <http://www.anvisa.gov.br/reblas/reblas_publicacoes_bac_cresc.pdf>. Acesso em: 26 nov.2012.

3 ANVISA. Padronização dos testes de sensibilidade a antimicrobianos por disco-difusão: norma aprovada. 8. ed. 2003a. (NCCLS. Document, M2-A8, v. 23 n.1.) Norma de aplicação global desenvolvida através do processo consensual do NCCLS. Disponível em: <http://www.anvisa.gov.br/reblas/reblas_public_disco_difusao.pdf >. Acesso em: 26 Nov. 2012.

4 BAKKALI. F., AVERBECK. S., AVERBECK, D., IDAOMAR, M. Biological effects of essential oils - A review. Food and Chemical Toxicology, v. 46, p. 446-475, 2008.

5 BARON, E. J.; PETERSON, L. R.; FINEGOLD, S. M. Diagnostic Microbiology. 9a Ed, MosbySt.Louis, Missouri, 958p, 1994

6 BOZIN, B.; MIMICA-DUKIC, N.; SIMIN, N.; ANACKOV, G. Characterization of the volatile composition of essential oil of some lamiaceae species and the antimicrobial and antioxidant activities of the entire oils. Journal of Agriculture and Food Chemistry, v.54, p.1822-1828, 2006.

7 BRANDL, M. T. Fitness of human enteric pathogens on plants and implications for food safety. Phytopathology, v.44, p.367-392, 2006.

8 BURT, S. A. Antibacterial activity of essential oils: potential applications in food. 2007. 136 f. Ph.D. thesis. Institute for Risk Assessment Sciences, Division of Veterinary Public Health. Utrecht University. Utrecht. The Netherlands.

9 BURT, S.A. Essential oils: their antibacterial properties and potential applications in foods - a review. International Journal of Food Microbiology, v.94, p.223-253, 2004.

10 CALSAMIGLIA, S., BUSQUET, M., CARDOZO, P.W., CASTILLEJOS, L., FERRET, A. Invited review: essential oils as modifiers of rumen microbial fermentation. Journal of Dairy Science, v.90, p.2580-2595, 2007. 
11 CRAVEIRO, A.A.; MATOS, F.J.; ALENCAR, J.W. A simple and inexpensive steam generator for essential oils extraction. Journal of Chemical Education, v.53, n.10, p.652, 1976.

12 DEVLIEGHERE, F., VERMEULEN, A., DEBEVERE, J. Chitosan: antimicrobial activity, interactions with food components and applicability as a coating on fruit and vegetables. Food Microbiology, v.21, p.703-714, 2004.

13 DEMETZOS, C.; PERDETZOGLOU, D. K. Composition and antimicrobial studies of the oils of Origanum calcaratum Juss. and O. scabrum Boiss et Heldr from Greece. Journal of Essential Oil Research, v.13, p.460 - 462, 2001.

14 FERREIRA, M.S.C., FONTELES, M.C. Aspectos etnobotânicos e farmacológicos do Cymbopogon citratus Stapf (capimlimão). Rev. Bras. Farm., Rio de Janeiro, v. 70, n. 4, p. 94-97, 1989.

15 FISHER, K.; PHILLIPS, C. A. Potential antimicrobial uses of essential oils in foods: is citrus the answer? Trends in Food Science and Technology, v.19, p.156-164, 2008.

16 GANDHI, M.; CHIKINDAS, M. L. Listeria: a foodborne pathogen that knows how to survive. International Journal of Food Microbiology, v.113, n.1, p. 1-15, 2007.

17 GUTIERREZ, J.; BARRY-RYAN, C.; BOURKE, P. Antimicrobial activity of plant essential oils using food model media: Efficacy, synergistic potential and interactions with food components. Food Microbiology, v. 26, 142-150, 2009.

18 GUTIERREZ, J.; RODRIGUEZ, G.; BARRY-RYAN, C.; Bourke, P. Efficacy of plant essential oils against foodborne pathogens and spoilage bacteria associated with ready-to-eat vegetables: antimicrobial and sensory screening. Journal of Food Protection, v.71, n.9, 1846 - 1854, 2008.

19 HOLLEY, R.A., PATEL, D. Improvement in shelf-life and safety of perishable foods by plant essential oils and smoke antimicrobials. Food Microbiology, v.22, p.273-292, 2005.

20 HSIEH, P.-C., MAU, J.-L., HUANG, S.-H. Antimicrobial effect of various combinations of plant extracts. Food Microbiology, v.18, p.35-43, 2001.

21 JUVEN, B.J.; KANNER, J.; SCHVED, F.; WEISSLOWICZ, H. Factors that interact with the antibacterial action of thyme essential oil and its active constituents. Journal of Applied Bacteriology, v.76, p.626-631,1994.

22 KOUTSOUMANIS, K., LAMBROPOULOU, K., NYCHAS, G. J. E. A predictive model for the non-thermal inactivation of Salmonella enteritidis in a food model system supplemented with a natural antimicrobial. International Journal of Food Microbiology, v.49, p.63 - 74, 1999.

23 NAZER, A. I.; KOBILINSKY, A.; THOLOZANA, J.-L.; DUBOIS-BRISSONNETA, F. Combinations of food antimicrobials at low levels to inhibit the growth of Salmonella sv. Typhimurium: a synergistic effect? Food Microbiology, v.22, p.391398, 2005.

24 NATIONAL COMMITTEE FOR CLINICAL LABORATORY STANDARTS - NCCLS. Methods for dilution antimicrobial susceptibility tests for bacteria that grow aerobically. $6^{\text {th }}$ ed. NCCLS document M7-A6 (ISBN 1-56238-486-4). NCCLS, 940 West Valley Road, Suite 1400, Wayne, Pennsylvania 19087-1898 USA, 2003b. Disponível em: www. anvisa.gov.br. Acesso em: 26 de novembro de 2012.

25 NATIONAL COMMITTEE FOR CLINICAL LABORATORY STANDARTS - NCCLS. Performance Standards for Antimicrobial Disk Susceptibility Tests; Approved Standard $-8^{\text {th }}$ ed. NCCLS document M2-A8 [ISBN 1-56238-4856]. NCCLS, 940 West Valley Road, Suite 1400, Wayne, Pennsylvania 19087-1898 USA, 2003a. Disponível em: www. anvisa.gov.br. Acesso em: 26 de novembro de 2012.

26 O'BRIEN, T. F. Emergence, spread, and environmental effect of antimicrobial resistance: how use of an antimicrobial anywhere can increase resistance to any antimicrobial anywhere else. Clinical Infectious Diseases, v.34, p.78-84, 2002.

27 ONAWUNMI, G.O.; YISAK, W.A.B.; OGUNLANA, E.O. Antibacterial constituents in the essential oil of Cymbopogon citrates (DC.) Stapf. Journal of Ethnopharmacology, v.12, p.279-286, 1984.

28 OUSSALAH, M., CAILLET, S., LAROIX, M. Mechanism of action of Spanish Oregano, Chinese cinnamon, and savory essential oils against cell membrane and walls of Escherichia coli 0157:H7 and Listeria monocytogenes. Journal of Food Protection, v.69, p.1046 - 1055, 2006.

29 SANTOS, I.; CUNHA, I. Patogênicos emergentes em alimentos. Segurança e Qualidade Alimentar, n.2, p.10 - 13, 2007.

30 SCHELZ, Z.; MOLNAR, J.; HOHMANN, J. Antimicrobial and antiplasmid activities of essential oils. Fitoterapia, v.77, p. 279-285, 2006.

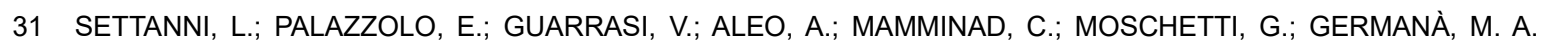
Inhibition of foodborne pathogen bacteria by essential oils extracted from citrus fruits cultivated in Sicily. Food Control, v.26, p.326-330, 2012.

32 TASSOU, C.; DROSINOS, E.H.; NYCHAS, G.-J.E. Effects of essential oil from mint (Mentha piperita) on Salmonella enteritidis and Listeria monocytogenes in model food systems at $4{ }^{\circ} \mathrm{C}$ and $10{ }^{\circ} \mathrm{C}$. Journal of Applied Bacteriology, v.78, p.593-600, 1995.

33 (WHO) World Health Organization Food safety and foodborne illness. Geneva, 2002. (Fact sheet, 237). 